Open Access

\title{
Using design-based research to develop a Mobile Learning Framework for Assessment Feedback
}

Mireilla Bikanga Ada(D)

Correspondence: Mireilla.
Bikangaada@uws.ac.uk
School of Engineering and
Computing, University of the West
of Scotland, High St, Paisley, UK

Correspondence: Mireilla Bikangaada@uws.ac.uk Computing, University of the West of Scotland, High St, Paisley, UK

\begin{abstract}
Students' lack of engagement with their assessment feedback and the lack of dialogue and communication for feedback are some of the issues that affect educational institutions. Despite the affordance that mobile technologies could bring in terms of assessment feedback, research in this area is scarce. The main obstacle for research on mobile learning assessment feedback is the lack of a cohesive and unified mobile learning framework. This paper thus presents a Mobile Learning Framework for Assessment Feedback (MLFAF), developed using a designbased research approach. The framework emerged from the observation of, and reflection upon, the different stages of a research project that investigated the use of a mobile web application for summative and formative assessment feedback. MLFAF can be used as a foundation to study the requirements when developing and implementing wide-scale mobile learning initiatives that underpin longitudinal practices, as opposed to short-term practices. The paper also provides design considerations and implementation guidelines for the use of mobile technology in assessment feedback to increase student engagement and foster dialogic feedback communication channels.
\end{abstract}

Keywords: Design-based research, Mobile learning, Assessment feedback, Framework

\section{Introduction}

Both student learning and student satisfaction are affected by assessment and feedbacktwo crucial elements of student experience. In fact, feedback has been recognised as one of the most crucial aspects which helps develop student learning (Black and Wiliam 1998). However, even after years of research and the increased adoption of technology to provide feedback, the assessment and feedback area is still a source of concern and continues to have a lower satisfaction rating than other areas in the National Student Surveys (NSS) (Boud and Molloy 2013). Meanwhile, the ubiquitous nature of mobile handheld devices is making mobile learning an attractive option in education. Mobile learning research has provided evidence that it can enhance, extend and enrich the concept and activity of learning itself (Traxler 2011), as mobile devices can 'support every pedagogic option, including the didactic and the discursive, the individual and the social' (Traxler 2010). However, the use of mobile learning in the educational sphere is still quite low as

(c) The Author(s). 2018 Open Access This article is distributed under the terms of the Creative Commons Attribution 4.0 International License (http://creativecommons.org/licenses/by/4.0/), which permits unrestricted use, distribution, and reproduction in any medium provided you give appropriate credit to the original author(s) and the source, provide a link to the Creative Commons license, and indicate if changes were made. 
compared to other areas of a mobile user's life. Mobile learning initiatives have focused in many areas of education, and different categories of mobile learning pedagogy are at different stages of development and research. A literature review by Bikanga Ada (Interrelationship between pedagogy, theories, objectives, and features: mobile learning design, n.d.) highlights the fact that many studies are still investigating attitudes towards mobile learning, indicating its level of infancy. One of the areas that is still in its infancy is assessment feedback in relation to mobile learning.

\section{Background and literature review} Assessment feedback

The importance of assessment and feedback in student learning has been explored in detail in previous literature. Reports and surveys (Ferrell 2012; NSS 2012) highlight student dissatisfaction with the assessment and feedback system. This 'troublesome issue' (Nicol et al. 2014, p. 102) has long been a challenge for both staff and students even before the introduction of the National Student Survey (NSS) and remains the weakest factor in NSS (Bell and Brooks 2017). Evans (2013) reviewed 460 articles on assessment feedback from 2000 to 2012 and found that most of the problems arise due to the fact that the student population has increased in higher education, due to which the unit of resource is being stretched and there is growing pressure on academic staff regarding traditional assessment. Bikanga Ada et al. (2017) investigated students' $(n=540)$ and educators' $(n=70)$ perception of assessment and feedback, and identified several issues that have also been highlighted in the literature. These issues include lack of student engagement and motivation with assessment feedback; educators being unhappy because, despite all their effort, students do not collect their assessment feedback; and high student numbers affecting the capacity to provide timely and personalised feedback (Bikanga Ada et al. 2017). Generally, formative and summative assessments are used to evaluate students. Formative assessments are tasks or activities that provide feedback to students on their learning, while summative assessments are used to evaluate students at the end of a course or a module. Assessment feedback is feedback provided to students upon completion of either a formative or a summative assessment. Despite the fact that many educational institutions' policies require feedback to be 'an interface between teachers' pedagogical goals; students' learning needs; and institutional and governmental education policies, which structure and regulate practices and procedures' (Bailey and Garner 2010, p.188), there is a decline in the practice of offering feedback to students (Charles et al. 2011). Providing feedback to students plays a vital role in increasing student achievement. Its ease of access has been identified as one of the aspects students value the most (Hepplestone et al. 2016), and one of the ways in which this access is facilitated is when the feedback is online. The potential for technologies to help educators provide feedback that is more personal and rich has been highlighted in various publications (Belshaw 2010). Crook et al. (2012) note that technology 'provide[s] the innovative edge that can help students engage more effectively with their feedback' (p. 387). A literature review (Interrelationship between pedagogy, theories, objectives, and features: mobile learning design, n.d.) highlights that despite various technologies, including audio, video, screencast and podcast, being used to alleviate the issues in assessment feedback, a larger class cohort still poses some problems to educators. These include 'extra workload, the inability to provide personalised and individual feedback, and the lack of synchronous 
or asynchronous communication or dialogue' (Interrelationship between pedagogy, theories, objectives, and features: mobile learning design, n.d.).

\section{Mobile learning}

Mobile devices can be the solution to increase students' access to their assessment feedback. Indeed, mobile technology fosters mobile learning, which 'accommodates and supports personal agency of the learner in a way that the learner can decide when, where and how he or she will learn; as such, mobile learning is instrumental in just in time and on-demand learning' (Khaddage et al. 2016, p. 16). Moreover, the affordances of mobile technology include portability, data gathering, communication, interaction with the interface, contextual and active learning, outdoor environment, multimedia creativity and the control of other devices (Parsons et al. 2016). Furthermore (Sung et al. 2016), mobile devices can also be used as tools for stimulating motivation, strengthening engagements and delivering content.

However, Pimmer et al.'s (2016) systematic review of empirical studies on mobile and ubiquitous learning shows that 20 years of mobile learning research has provided little systematic knowledge on the use of mobile technology in different educational designs and the associated educational effects in higher education settings. Furthermore, in the past decade, many studies using student-owned mobile handheld devices have focused on the concept of text messaging (Gemmell et al. 2010; Harley et al. 2007; Naismith 2007; So 2016; Timmis 2012). Despite the growing research involving mobile devices and the social media applications they encompass (Ahern et al. 2016; Gan and Balakrishnan 2017; Ledford et al. 2015; So 2016), and despite the knowledge that mobile learning brings new opportunities for feedback provision (Gaved et al. 2013), the literature on empirical research about using students' mobile handheld devices for assessment feedback is relatively small. Dearnley et al. (2008) explored the feasibility and identified the issues related to using mobile technologies in the assessment of health and social care students in practice settings. The impact of the mobile devices on the assessment processes and outcomes was positive in general, despite students resenting the use of these devices as they did not belong to them. Another study in which students did not like the devices provided by the university was conducted by Taylor et al. (2010). They introduced mobile learning into health and social care $(\mathrm{H} \& S C)$ practice placement learning and assessment. The focus of the study was on mobile assessment and a variety of sources of formative feedback that fostered student reflection and deducing further action to improve performance. Dann and Allen (2013) studied the use of iPhone for providing formative assessment to students and other stakeholders within the educational sector. The study shows that feedback that is available on the web and is accessible using mobile devices can increase the opportunity for reflection at a convenient time. Campbell and Morrison (2007) developed a web-based content management system called Just in Time Medicine (JIT), an assessment and feedback tool that captured learner progress related to hundreds of clinical skills. The study involved 367 medical students. This study showed that smartphones and tablets are useful in the process of medical learning and technical assessments. However, the feedback associated with their grades was generated automatically and limited to 'Well done,' 'Needs improvement', or 'Not done/unsatisfactory'. Soh and Ho (2014) studied the use of mobile Applications (m-Apps) by 80 students in a private university in Malaysia to provide dialogic feedback on students' writing tasks. m-Apps enabled students' access to the learning 
material using their smartphone. The positive outcomes of this study include the flexibility of accessing the learning material anytime and anywhere, besides adding to the usefulness, comprehension and transferability of the learning material (p.46).

The limited use of mobile learning within the area specific to assessment feedback is not surprising. Kukulska-Hulme et al. (2011, p. 19) note that mobile technologies will not necessarily be readily adopted for learning, as there are a variety of barriers to adoption. Furthermore, the popularity of mobile handheld device among students and their familiarity with the device does not necessarily make mobile learning attractive (Merchant 2012). A critical issue is the pedagogical integration of technological tools into the curriculum (Kong 2015). Educators need to incorporate ways of leveraging the flexibility of boundary crossing to enhance learning across a multitude of contexts (Schuck et al. 2017, p. 128) by ensuring that both instructional materials and delivery methods are put into a mobile format and remain flexible in different usage environments and situations.

One of the barriers to wide-scale adoption is the lack of confidence educators have in their abilities to use mobile learning strategies. They need to be explicitly guided and supported to adopt these approaches (Parsons et al. 2016). For example, there is a need to develop methods and strategies to generate examples of how to relate and link learning across contexts (Khaddage et al. 2015, p. 627). Additionally, the diversity of mobile learning initiatives and mobile learning frameworks presents a real challenge in higher education (Wishart and Green 2010), including the lack of 'transferable design framework,' 'evaluation of the projects' and 'explicit underlying pedagogical theory' (Cochrane, 2014, p. 67). This has led to many researchers highlighting the need for a unified framework (Sølvberg and Rismark 2012) that supports the ecology of mobile learning (Khaddage et al. 2015) and can guide effective instructional design and evaluate the quality of programmes that rely significantly on mobile technologies (Park 2011).

Many frameworks have been designed to address many aspects of mobile learning in general (Crook et al. 2012; Kearney et al. 2012; Koole 2009; Laurillard 2007; Motiwalla 2007; Ozdamli 2012; Park 2011; Parsons et al. 2007). These frameworks share the same overarching themes of pedagogy, learner, context, content, time, social interactions, usability, device and culture, but none of them has a particular focus on assessment feedback. In their literature review on existing mobile learning models and frameworks, Hsu et al. (2014) observed that most frameworks and models focused on 'pedagogies and learning environment design'. This category of frameworks highlights practical checklists to guide educators to identify the components that serve as a foundation in their mobile learning initiatives. Although the second most common type of frameworks and models, 'platform/system design', also involves pedagogies and learning environment design, the focus is generally on the technical aspects. The authors identified only one framework that focuses on evaluation (Vavoula and Sharples 2009), highlighting the scarcity of such frameworks. A framework for evaluating mobile learning should help evaluate each phase of the mobile learning initiative. The framework presented in this paper encompasses these three categories.

To summarise, despite the affordance that mobile technologies could bring in terms of assessment feedback, research on use of mobile learning for assessment feedback is scarce. The main obstacle in adopting mobile learning is the lack of a cohesive, unified mobile learning framework. Considering all the above limitations, the research reported 
in this paper proposes to address some of the limitations by developing a Mobile Learning Framework for Assessment Feedback. The framework will serve as a guide through the design, development and implementation of the mobile learning initiatives besides being used by educators to evaluate mobile learning outcomes.

\section{Purpose of the study}

The purpose of the study was to develop a Mobile Learning Framework for Assessment Feedback (MLFAF) through observation of, and reflection upon, the different stages of a research project that uses a mobile web application for assessment feedback. As part of the project, a mobile web application, MyFeedBack, was developed, which enabled the personalisation of group feedback. Group feedback and the associate grades were uploaded once and kept in each student's account. They were then modified to reflect their individual contributions to the group coursework, where applicable, and then posted to the students' feedback page. The students would then need their login details to view their own feedback. Uploading just one feedback and making a few changes to the same feedback made the process of feedback provision faster than writing and uploading each feedback individually. Figure 1 (Interrelationship between pedagogy, theories, objectives, and features: mobile learning design, n.d.) shows an example of group feedback as seen on a student's feedback page. MyFeedBack also enabled monitoring of feedback access and allowed students access to feedback using any device, including mobile handheld devices. A full description of the application is available online (Bikanga Ada 2013a, 2014a). Results reported in this paper focus only on presenting the development phases and evaluation of the framework.

The study explored the following research question:

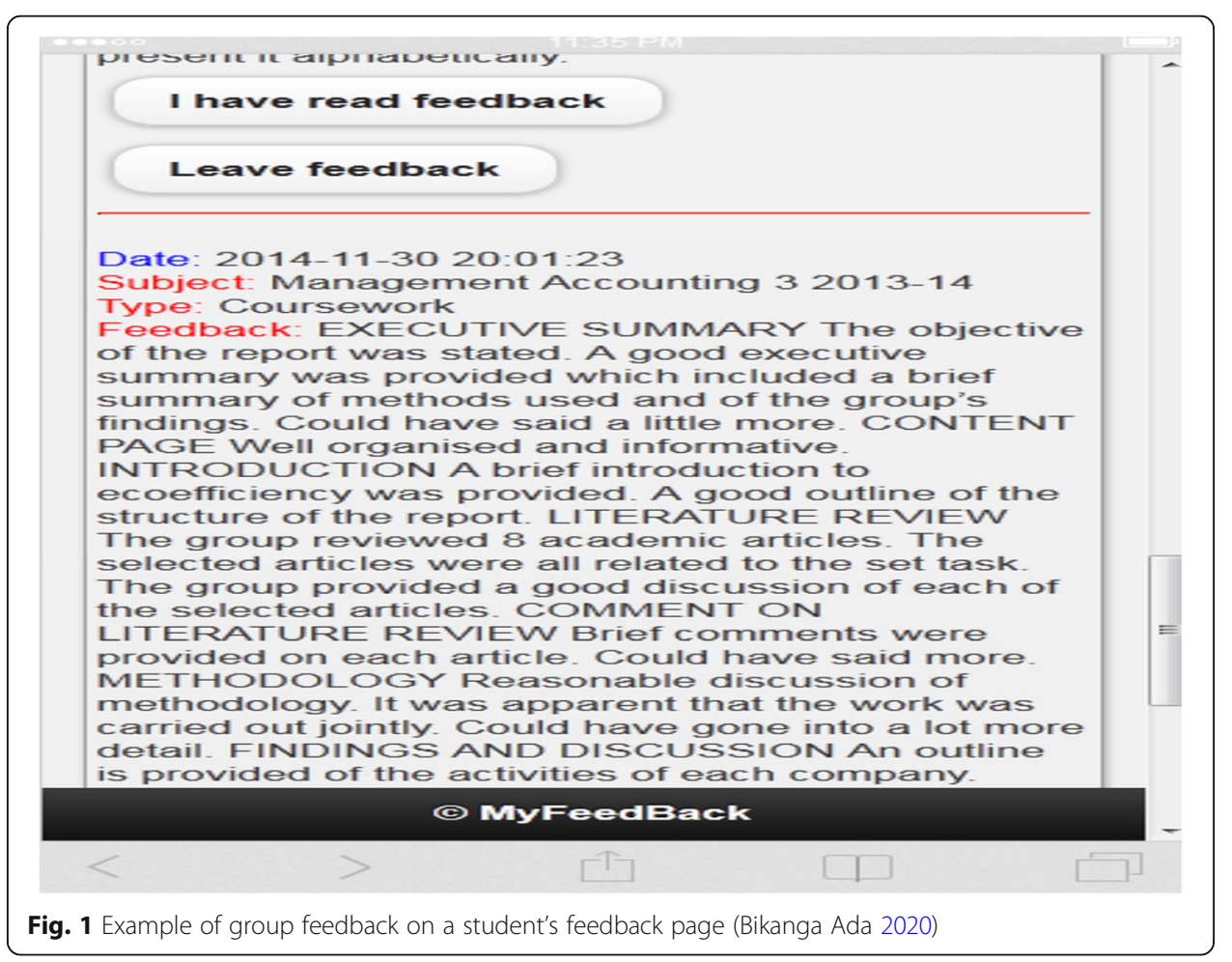


- 'What design principles and framework should educators follow in creating mobile learning initiatives, and what pedagogical strategies can best be deployed to enhance student engagement with their assessment feedback and foster dialogic feedback communication channels between educators and students?'

\section{Method}

\section{Design-based research}

The research study is set within the overall framework of design-based research. Wang and Hannafin (2005) defined design-based research as 'a systematic but flexible methodology aimed to improve educational practices through iterative analysis, design, development, and implementation, based on collaboration among researchers and practitioners in real-world settings, and leading to contextually-sensitive design principles and theories (p. 6)'. The use of design-based research methodology in educational contexts has increased over the past decade and mostly with educational technology innovations and interventions (Anderson and Shattuck 2012, p.25). Its increased use is in response to some traditional research methodologies failing to link theory and practice within the educational practice (Alghamdi and Li 2013, p.3). Design-based research is conducted in real-world contexts (educational settings) due to the complexity of the problems it addresses (Hsu and Ching 2015, p.31). It gives researchers and practitioners the opportunity to produce tools, approaches, theories and products that have been tested in the field and are effective (McKenney and Reeves 2012). The first reason a design-based research approach was adopted in this study is because this research study was situated in real educational context (assessment feedback and mobile learning in higher education). The second reason is the use of new technologies such as student-owned mobile devices and a mobile web application. Recognising the important role of technology in shaping education is fundamental to design-based research. In fact, Amiel and Reeves argue that 'if we persist in believing in education and technology as value-free, we should not attempt to engage in design-based research and should instead resign ourselves to perpetuating research that effects no systematic change' (2008, p. 37). With the main focus being on the design and testing of the interventions in order to provide a possible solution to the problem of assessment feedback provision in large classes and lack of student engagement with that feedback, the third reason for adopting a design-based approach was to produce a Mobile Learning Framework for Assessment Feedback (MLFAF) and guidelines.

The study used McKenney and Reeves' (2012) generic model for design research (GMDR) , another name for design-based research, which has three main phases: analysis and exploration, design and construction, and evaluation and reflection. Design-based research follows a cyclic process containing cycles of analysis, design, evaluation and revision that enable the improvement of the interventions over time. Following these iterative cycles, the GMDR phases connect with 'ongoing practice as the intervention is adopted, enacted, and sustained (implementation) in a particular educational setting while information about the intervention is disseminated and diffused to a wider audience.'(Kukulska-Hulme et al. 2011).

\section{Participants, settings and design}

The research project that enabled the development and evaluation of the MLFAF was conducted in a university in the UK. The focus of the learning activities involved summative 
and formative assessment feedback. Following the phases of GMDR, the study started with a literature review, followed by initial fact-finding studies involving both lecturers and students. The purpose of the fact-finding studies (survey and follow-up interviews) was to seek participants' views in relation to assessment feedback and mobile learning (Bikanga Ada et al. 2017). The first draft of the framework emerged from the literature review and was updated after the initial (explorative) fact-finding studies. These corresponded to the analysis/exploration phase of GMDR.

The second phase of the study was concerned with the design and development of a mobile web application, 'MyFeedBack'. The features of MyFeedBack enabled educators to personalise group feedback and monitor student feedback access, and enabled student access to the feedback using any device, including their mobile handheld devices (Bikanga Ada 2014a). This phase also included early trials of the application, which contributed to the identification of the issues that influenced students' use of their own devices for mobile learning (Bikanga Ada 2013b), and the investigation of whether students' grades influenced their decision to access feedback (Bikanga Ada 2014b). This phase, which corresponds to the design/construction phase of the GMDR, triggered further updates of MLFAF.

The last phase was concerned with the evaluation of three studies. In study 1 and 3, students' summative assessment results (feedback and grades) were uploaded on MyFeedBack, and students in study 2 received only their formative assessment feedback. Participants in study 1 were from the Schools of Health, Nursing and Midwifery (HNM) and Business $(n=218)$. Those in study 2 came from the School of Computing $(n=79)$, and students in study 3 were from the Business School $(n=148)$. While results from observation and digital footprinting from the studies have been disseminated (Bikanga Ada 2014c; Bikanga Ada and Stansfield 2017), the publication reporting on the quasiexperiments' results, which were positive, is currently under review. The final version of the framework emerged from this phase, which corresponds to the evaluation/reflection phase of the GMDR. Here, the framework went through iterative evaluation, reflection and revision cycles of the individual study, spanning 3 years.

The next section reconstructs the development and evaluation phases of the framework and briefly explains the context surrounding each update of MLFAF.

\section{Results and Discussion}

Mobile Learning Framework for Assessment Feedback design and evaluation cycles Initial draft based on the literature review

The initial draft of MLFAF had its foundation in previous mobile learning frameworks and the literature review. It brought forward various aspects that have been identified as crucial in mobile learning, including ownership, context, pedagogy, communication and dialogue, and exploration. These aspects of MLFAF have been selected because, altogether, they emphasise the idea of crossing the current boundaries that have existed for so long in educational institutions, thus enabling realms of unprecedented types and levels of engagement and connectivity in a student-centred environment.

Ownership Ownership, which is a key motivational feature (Jones et al. 2006), is about learning in a student-centred environment (Barbara 2010) where students are empowered to make their own decisions facilitated by their own devices. In this learning environment, 
students can address their own learning interests and needs (Nanney 2004, p. 1). However, the aspect of ownership, which is at the core of this initial draft of the framework, is not only about ownership of the devices, but also encompasses some of the other dimensions that emerged from previous frameworks and literature as contributing factors to mobile leaning (Deng and Tavares 2013; Jones and Issroff 2007; Jones et al. 2006; Kearney et al. 2012; Koole 2009; Laurillard 2007; Park 2011; Parsons et al. 2007). It is about students reclaiming control over the devices that suit their taste or convenience and suit the time they want to access their content, where they want to access that content and the pace at which they interact with it. It is about student motivation and being in control of their choices in a student-centred environment.

Pedagogy Another important aspect, pedagogy, which is defined as 'any conscious activity by one person to enhance learning in another'(Mortimore 1999, p. 17), has been mentioned in mobile learning frameworks (Ozdamli 2012). One such pedagogical activity is personalisation, which is a key aspect identified in many mobile learning frameworks. For example, it enables students to self-control their learning process (Kearney et al. 2012) and to control the content (Motiwalla 2007). Also, personalisation of the content, for instance, requires that educators ensure that the assessment feedback is personalised, reflecting individual student contribution. Furthermore, the benefits of personalised and individual feedback have been highlighted in the literature (Ferguson 2011; Taylor and Burke da Silva 2014). Based on these findings, the pedagogy aspect was added to the framework.

Communication and dialogue Many frameworks (Kearney et al. 2012; Koole 2009; Laurillard 2007, 2009; Motiwalla 2007; Park 2011) have highlighted communication and dialogue as key factors in education. With regard to assessment feedback, the literature emphasises on the importance of dialogue between learners and teachers. For instance, communication issues in feedback have been greatly reported due to the tendency of feedback being a monologue process from teachers to students (Bloxham and Campbell 2010). The conversation theory (Laurillard 2007, 2009) advises that successful learning needs constant twoway conversations and interactions between the educators and learners, and between learners. Communication and dialogue are about building those links between learners and teachers. In light of these findings, communication and dialogue were also identified as vital aspects of the Mobile Learning Framework for Assessment Feedback.

Context Another aspect that appears in some frameworks is context (Kearney et al. 2012; Koole 2009; Parsons et al. 2007). Despite its importance, many mobile learning frameworks and models have failed to discuss this aspect (Imtinan et al. 2013). Kearney et al. look at context as an expansion of learning in the real world and community. In Koole's framework, the context of information is what influences mobile learning experiences. In this study, this context of information refers to the context of feedback and access to feedback in authentic contexts. Furthermore, each dialogic communication link between the educator and the student is set within a one-to-one, personalised and individual context, where ideas are negotiated through synchronous or asynchronous exchanges. Context is, therefore, another critical aspect of the framework. 
Exploration There is a need for greater understanding of the problems in assessment and feedback practices. Li and De Luca (2014) recommend the starting point be investigating the assumptions and beliefs of stakeholders in assessment practices. It is therefore essential to understand the university's culture of assessment and feedback and the use of technology-enhanced assessment feedback, investigate whether issues identified in the literature are the same within the institution and investigate the institution's policies to identify the problems that enhance or hinder the adoption of assessment and feedback policy and its implementation. This dimension is called assessment and feedback culture and policy.

On the other hand, literature has identified mobile learning as a key element in the transformation of education. However, literature also indicates that students may be unwilling to use a device that does not belong to them (Dearnley et al. 2008; Taylor et al. 2010) or may not want to use their own device (Franklin 2015). Therefore, students' own choice to participate in mobile learning using a device of their choice could foster engagement in mobile learning activities (Ferreira et al. 2013). Nonetheless, it is essential to investigate the level of device ownership. This dimension is called device ownership.

It is also important to identify whether users would want to use the application (Lazar et al. 2010). Before introducing any form of mobile learning, students' perceptions of mobile learning need to be investigated or their readiness considered (Cheon et al. 2012; Corbeil and Valdes-Corbeil 2007), as learners may not be willing to accept it (Wang et al. 2009). Also, there is a need to implement ways to find out if and how students make use of the provided feedback (Price et al. 2010) to understand the feedback culture. This dimension is called willingness and attitude. It is equally important to investigate whether current technology has the potential to enable the mobile learning activities planned or to help solve the identified issues such as those identified in this research. This dimension is called IT infrastructure. All these four dimensions justify the exploration aspect in this initial framework.

\section{Framework updates based on fact-finding studies}

The aspect of exploration, which suggested looking into various aspects, including assessment and feedback culture and policy, IT infrastructure, device ownership and attitudes/ willingness, was tested using initial fact-finding studies in a university (Bikanga Ada et al. 2017). Findings consolidated the importance of the aspects of the framework in which ownership has a central place as it enables students to use their devices anytime and anywhere for everything, including learning. Thus, technology is seen as a culture, and institutions should tape into these affordances to connect with their students.

The following section describes the changes that were made to the first draft of the framework as a result of the findings from the initial fact-finding studies.

\section{Pedagogy (updated)}

- Mobile learning boundaries - The results from fact finding revealed that the teaching staff feared being 'always connected'. It is therefore important to set the boundaries before initiating any mobile learning activities. Students should also be informed when to expect a mobile learning activity and when to contact their lecturer on the mobile learning environment to eliminate the teaching staff's fear of having to be 'always connected'. 
- Feedback culture change - Results revealed the need to educate both students and tutors on feedback. For example, there were two educators who did not know what feedforward was. On the other side, some students did not recognise feedback. Educators need to reinforce the importance of feedback in student learning enhancement and subsequently for the institution as a whole. Tools such as MyFeedBack or similar that enable the change in students and educators' feedback culture should be provided.

ICT infrastructure The findings also enabled the enunciation of the pedagogical and technical requirements for a mobile web application (Bikanga Ada 2013a, Bikanga Ada 2014a, 2014b, 2014c). Based on this, another aspect, ICT infrastructure, was added to the framework.

\section{Framework update based on application development and early trials}

Based on the infrastructure requirements identified that led to the addition of the ICT infrastructure aspect, a mobile web application, MyFeedBack (Bikanga Ada 2013a, Bikanga Ada 2014a, 2014b, 2014c), was developed. As a result of MyFeedBack development and early trials (Bikanga Ada 2013b, p. 2495), the following dimensions were added to the framework:

\section{Context (updated)}

- Curriculum - The findings from early trials showed that for a successful integration of mobile learning using student devices, the integration of mobile learning technology into the course design is necessary. The relevance of the mobile learning activities is crucial as the trials highlighted the lack of engagement by students in mobile learning when the topic was not relevant.

\section{Pedagogy (updated)}

- Participation - The right of educators or students to not participate should be respected. However, to ensure uptake of mobile learning, educators' participation is crucial and strongly recommended. It was observed that some students did not participate because their lecturer was not using MyFeedBack, hence the importance of interactivity.

- Choice and flexibility - Enable participants to make their own decisions (anytime, anywhere and using any device). Students used different devices during the trials. One crucial point was the shift of paradigm which requires considering the students as the pivotal point of learning. A student-centred learning therefore consists of the need to give students the choice and freedom to use any device to access their learning material and remove the exclusive focus on student-owned mobile handheld devices, which students may not be willing to use (Franklin 2015). Therefore, lecturers need to implement activities that enable flexibility and choice, activities that are 'device-agnostic' (Koole et al. 2010).

\section{ICT infrastructure (updated)}

- Digital education - Both lecturers and students had some difficulties using the application. Educating the teaching staff on how to use the mobile learning platform for 
assessment feedback and how to add content will help to overcome confidence issues about using a new form of technology-enhanced assessment feedback. Demonstrating to students how to use their own mobile handheld device or any device of their choice for learning will help overcome any resistance due to confidence and communication issues. Provide a demonstration for both students and lecturers, which could be achieved through regular meeting sessions where staff and students can practice using the mobile learning platform.

- Technical support - Provide more technical support to teaching staff than they usually receive. Facilitate use of the mobile learning platform from the very beginning by allowing the teaching staff to experiment with it.

Figure 2 presents the Mobile Learning Framework for Assessment Feedback based on the literature review, fact-finding studies, and application development and early trials.

\section{The iterative cycles of evaluation, reflection and revision of MLFAF}

Corresponding to phase 3 of GMDR, 'evaluation and reflection', the purpose of this section is to evaluate and further develop the framework. The objective is to explore how the dimensions in ownership (e.g. device, learning, pace, space, time, motivation, control, engagement), context (e.g. feedback, curriculum), communication and dialogue (e.g. asynchronous, synchronous) and pedagogy (e.g. feedback personalisation, choice and flexibility) emerged in the studies and how they related to each other. The revision of the framework, where applicable, was based on the findings from the observation of the three studies and the qualitative data acquired from participants. Figure 3 presents a graphical description of the iterative cycles of evaluation, reflection and revision of MLFAF.

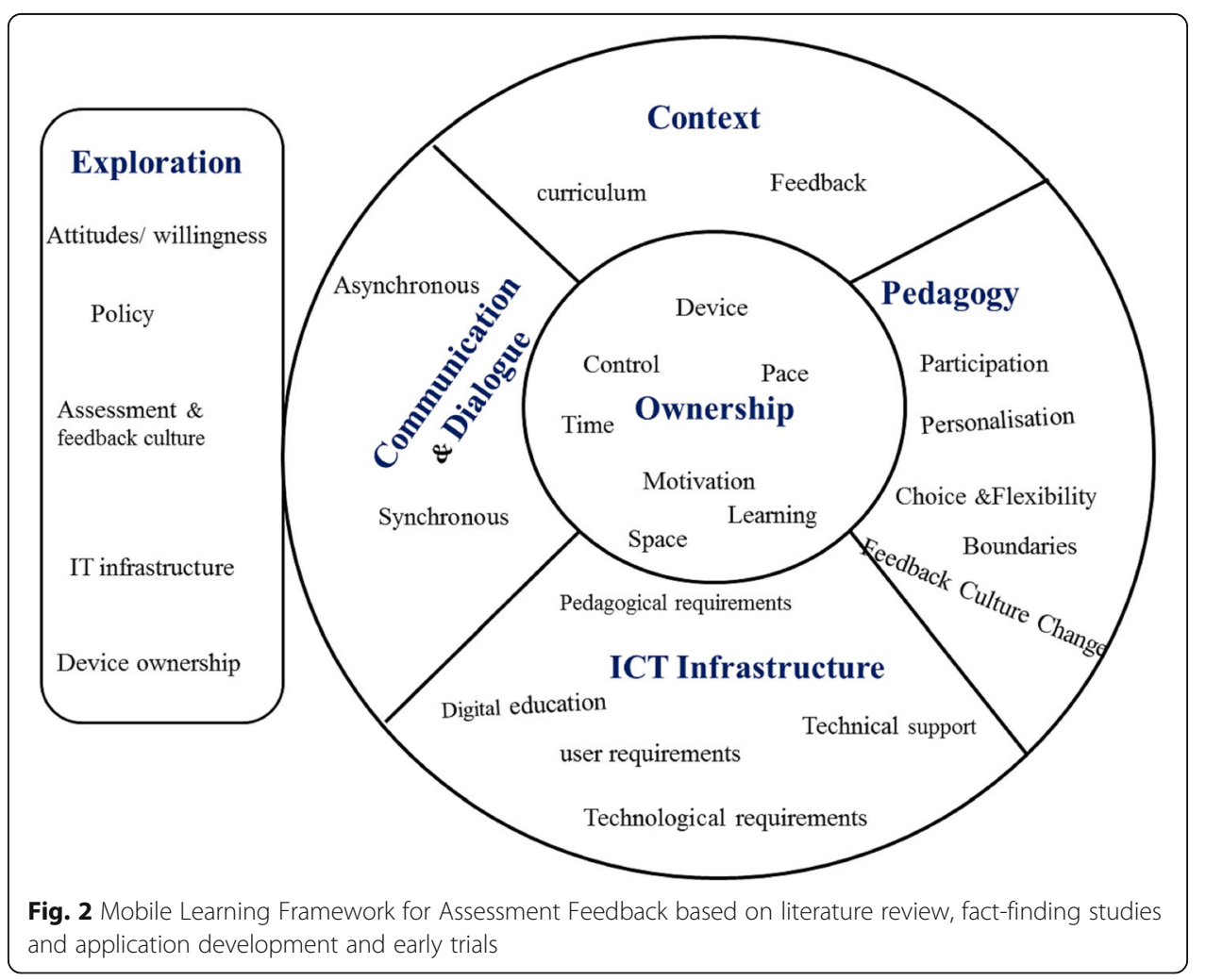




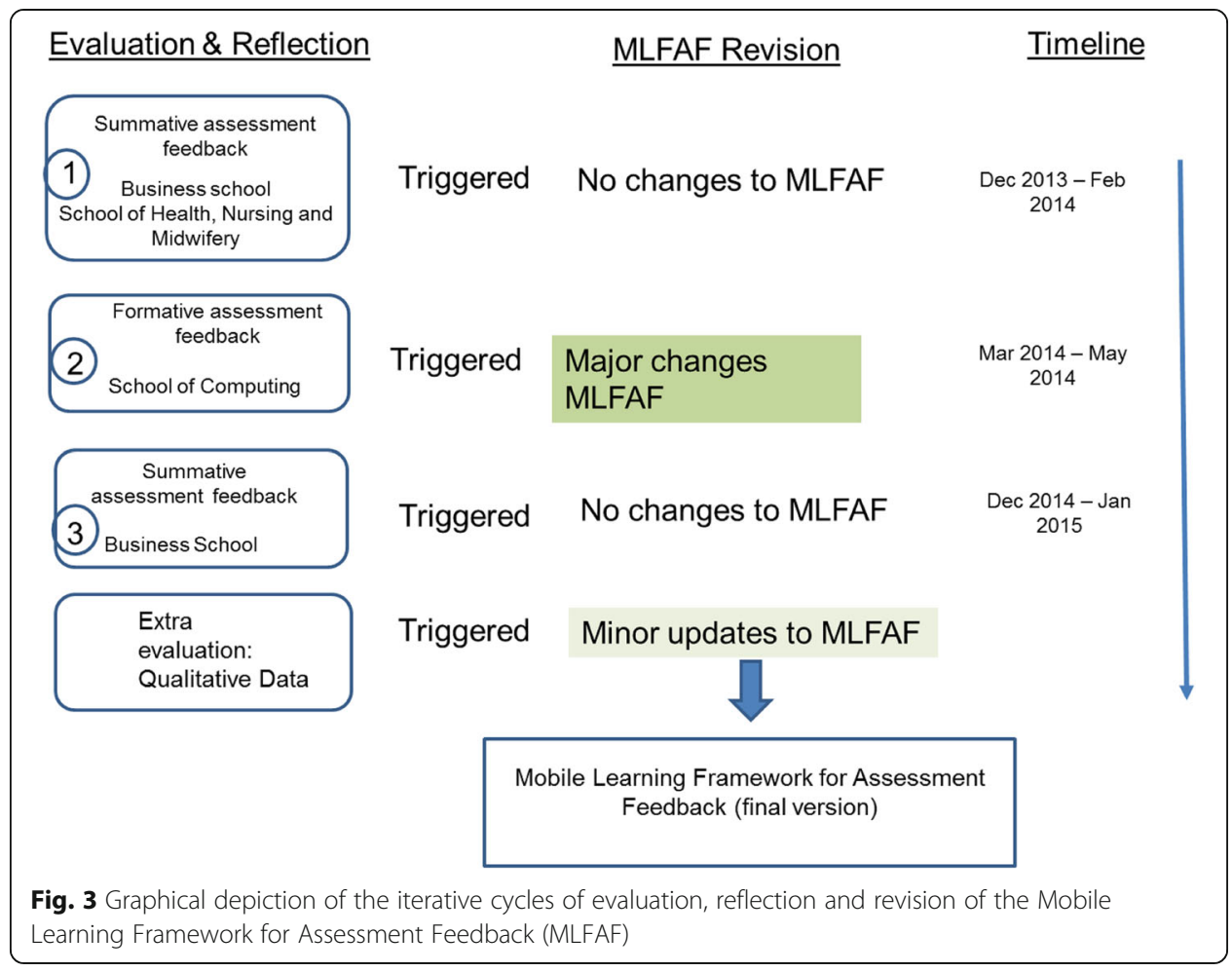

\section{MLFAF evaluation: Study one-summative assessment feedback}

The evaluation in study linvolved summative assessment feedback in the Schools of Health, Nursing and Midwifery (HNM) and Business $(n=218)$. Group assessment results were uploaded by the lecturers who would subsequently update individual student feedback and marks/grade to reflect their contribution where applicable. Using MyFeedBack to provide assessment feedback meant that students were able to access relevant feedback in authentic contexts. Students received their assessment feedback at the end of term 1, just at the beginning of their Christmas holiday (2013), implying that the feedback was accessed mostly out of the university. Students also accessed their feedback using their own devices, and many used their mobile handheld devices (smartphones and tablets) and sometimes a combination of any device. This enabled them to be in control and gave them the choice and flexibility to use a device of their choice. Log details in the database showed that access to feedback was done at any time of the day and night. Most students accessed the same assessment result on several occasions. Results showed the importance of having a tool that enables communication and feedback dialogue between students and lecturers through any device, as there was an increase in communication between the lecturer and students (Bikanga Ada 2014c). Some participants needed further help after the initial demonstration, highlighting the importance of technical support and digital education. It is evident that the potential of the aspects of the framework were achieved at this stage. It was therefore not necessary to update the framework. However, it also highlights the need for strong technical support and demonstration.

\section{MLFAF evaluation: Study two-formative assessment feedback}

Study 2 involved participants from the School of Computing $(n=79)$. Although students were able to access their formative feedback in authentic contexts using any device, many 
participants in this group did not disclose the devices they used. Compared to study 1 , this study had the highest number of students accessing their feedback, but most did it just once (Bikanga Ada and Stansfield 2017). Thus, engagement with assessment feedback, though still evident, was low. This study was significantly different from study 1 , in that the communication and feedback dialogue that was observed as one success factor was now non-existent in study 2. The lecturer's participation was limited to just posting the group feedback to students. Although the feedback reached individual students on their own page where they could read it in their own privacy, it was not personalised, which could have undermined student engagement with their formative assessment feedback. It was evident that the potential of all the elements of the framework was not achieved; some dimensions of the pedagogy aspect were missing. Study 2 supported some aspects and interrelationships of the framework but failed to initiate and enhance communication and feedback dialogue.

The importance of pedagogy and pedagogical practices was evident in this study, giving a new direction to the framework. The ownership aspect, which had been at the core of the framework since the initial draft, was now replaced by the pedagogy aspect. With pedagogy at the core of the framework, its relationship with the other components of MLFAF is reciprocal and mutually influential. The ownership aspect does not necessarily lead to the communication and feedback dialogue aspect even when an ICT infrastructure that leverages the dimensions in the ownership aspect is available, as found in study 2. It is the pedagogical practices that influence communication and dialogue, facilitated by an appropriate ICT infrastructure. Ownership, however, links to pedagogy, as the pedagogical practices should ensure that the dimensions of ownership such as time, pace, space, control, device and learning are taken into consideration. In other words, considering the students as pivotal factor shapes the pedagogical practices. Pedagogy alone does not influence communication and dialogue. It needs the means by which this can be achieved (ICT infrastructure). On the other side, pedagogy affects the choice of infrastructure.

Figure 4 shows the revised framework which now has pedagogy as the core component. It shows that student engagement with their assessment feedback happens at the intersection between pedagogy, context and ICT infrastructure $(P C I)$, while communication and feedback dialogue occurs at the intersection between pedagogy and ICT infrastructure (PI). Meanwhile, ownership fosters access to feedback in authentic contexts. The relationship between ownership and ICT infrastructure is also reciprocal and mutually influential.

\section{MLFAF evaluation: Study three-summative assessment}

The newly revised framework, which puts pedagogy at the core, was further tested in study 3 (summative assessment feedback) with participants from the Business School $(n=148)$. The contexts were similar to that in study 1 . The lecturer was one of those who participated in study 1 . Success from the previous year had motivated her, and so, she decided to use MyFeedBack for the same group report assessment but with a different student cohort. Similar to study 1 , the potential of the components of the framework was achieved, and the same conclusions were drawn. However, there was an increase in student engagement that was linked to the increase in the lecturer's active participation on MyFeedBack, reinforcing the central place of pedagogical practices in the framework. 


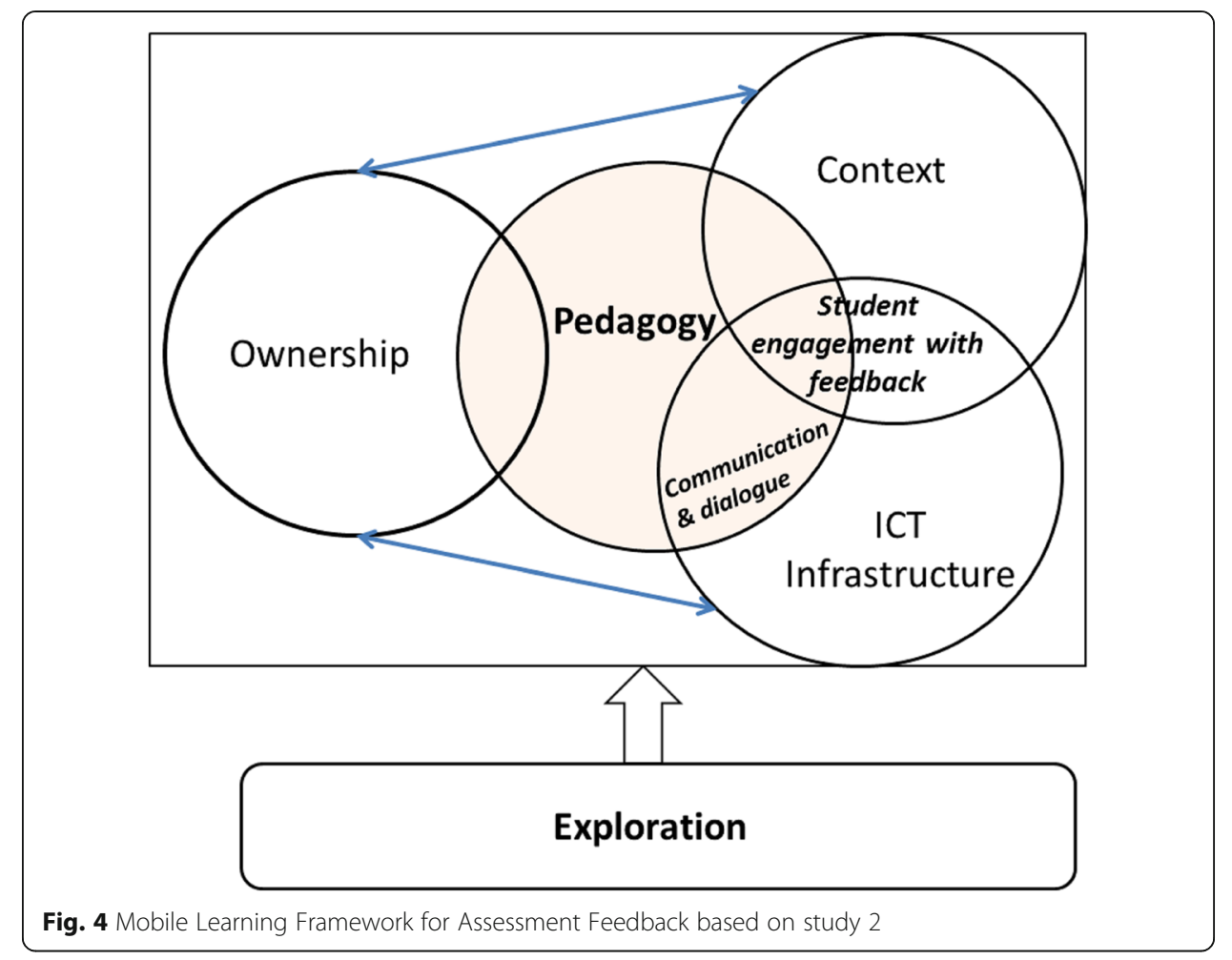

\section{MLFAF evaluation: Qualitative data}

Data from students emerged from the additional comments students left when they took the survey after using MyFeedBack application. It reinforced the place of the elements of the framework as already discussed in the studies. However, few students highlighted the difficulty in using MyFeedBack (technical support/digital education). Another issue that emerged was the timing of the feedback. Although feedback was quickly provided and was accessible anytime and anywhere using any device, some students felt that they were too busy with their exam preparation to really engage with it. Lecturer *Amina* (summative studies 1 and 2) stated that using MyFeedBack has changed the way she provides feedback and has empowered her students. Furthermore, she said that she has become more motivated as a result of her students' engagement with assessment feedback and the dialogic feedback channels that emerged.

The framework was then revised to highlight the fact that student engagement with the feedback influences the shift in the lecturer's pedagogical practices and increases the lecturer's motivation. Moreover, the change in pedagogical practices is influenced by the lecturer's own competency. Figure 5 presents the final version of MLFAF, with all the components organised in three main sections: Needs assessment, Development/ implementation and Outcomes. The proposed framework is an answer to a part of the research question that asks what framework educators should follow when creating mobile learning initiatives.

How to use MLFAF for supporting assessment feedback?

MLFAF is mostly useful in situations where students' lack of engagement with their assessment feedback is evident and/or students are not commenting on the received 


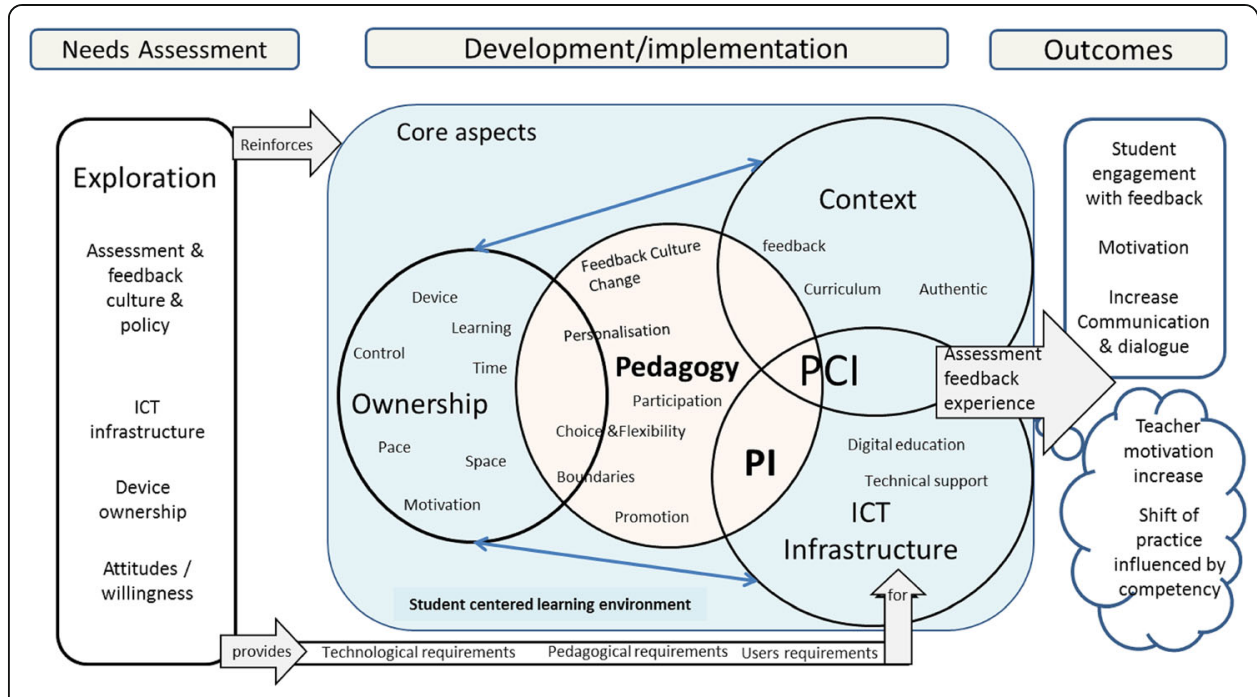

Fig. 5 Mobile Learning Framework for Assessment Feedback

feedback. Both issues often leave educators frustrated and disillusioned. MLFAF should be used as a stepping stone to ask all the correct questions, gather information, critically examine what is needed and what is happening, and reflect on what might need to be changed. MLFAF can also be used in other mobile learning activities. It is an ideal foundation to develop wide-scale mobile learning initiatives that underpin longitudinal practices as opposed to short-term formal/informal practices. It means adopting these practices for long term and making them the norm by including them in the curriculum instead of trying them once or twice and then abandoning them. MLFAF has three main sections: Needs assessment, Development/Implementation and Outcomes. Table 1 presents an example of a decision-making exercise that could guide the practitioners.

\section{Design guidelines for mobile learning assessment feedback}

This section answers part of the research question that asks about the design principles educators should follow in creating mobile learning initiatives.

The key elements and characteristics of the MLFAF framework are exploration, pedagogy, context, ICT infrastructure and ownership. The MLFAF framework has enabled the compilation of design considerations and implementation guidelines, which are as follows:

\section{Exploration}

Practices of assessment feedback are different between individuals and between institutions. Exploration helps with the identification of the issues, assumptions and beliefs of stakeholders that affect the area of mobile learning undertaken. It is concerned with an initial fact-finding investigation that allows the understanding and specification of the context, the user requirements and the objectives in order to influence the design of the artefact. It enables looking into the current practice of assessment feedback, looking into the policy and the institution's culture, and investigating students' attitudes and the devices they own or use. It is also important to investigate the current state of technology available. 
Table 1 Example of decision-making exercise using MLFAF

\begin{tabular}{|c|c|c|c|}
\hline Section & Needs assessment & Ask questions & How to achieve that? \\
\hline \multicolumn{4}{|l|}{ Aspect } \\
\hline Exploration & $\begin{array}{l}\text { A preliminary } \\
\text { investigation is required } \\
\text { for any mobile learning } \\
\text { initiative. }\end{array}$ & $\begin{array}{l}\text { Is there an ICT infrastructure } \\
\text { to support the mobile learning } \\
\text { activity? } \\
\text { What does the policy say? } \\
\text { What is the current culture? } \\
\text { What type of devices do } \\
\text { students own? } \\
\text { What do students } \\
\text { (and educators) think of the } \\
\text { mobile learning activities? } \\
\text { Will they be willing to participate? } \\
\text { How do I foster the Use My Own } \\
\text { Device attitude? }\end{array}$ & $\begin{array}{l}\text { Meeting with institution's ICT } \\
\text { personnel to identify what } \\
\text { enabling technology is available. } \\
\text { If none, develop one. } \\
\text { Check policy document and } \\
\text { assessment and feedback practices. } \\
\text { Consider surveys and interviews }\end{array}$ \\
\hline Section & \multirow{2}{*}{$\begin{array}{l}\text { Development and } \\
\text { implementation }\end{array}$} & \multirow[t]{2}{*}{ Ask questions } & \multirow[t]{2}{*}{ How to achieve that? } \\
\hline Aspect & & & \\
\hline Ownership & $\begin{array}{l}\text { Foster student } \\
\text { ownership of the } \\
\text { learning and of } \\
\text { the device. }\end{array}$ & $\begin{array}{l}\text { Are my learning activities } \\
\text { accessible using any device? } \\
\text { Can I enable online and/or } \\
\text { offline access? }\end{array}$ & $\begin{array}{l}\text { Produce device-agnostic learning } \\
\text { material. } \\
\text { Depending on available technology }\end{array}$ \\
\hline Pedagogy & $\begin{array}{l}\text { Any activity that would } \\
\text { improve student } \\
\text { learning. }\end{array}$ & $\begin{array}{l}\text { How do I change the feedback } \\
\text { culture? } \\
\text { How do I promote the activity? } \\
\text { What boundaries shall I set? } \\
\text { How will I manage my time? } \\
\text { What personal challenges will } \\
\text { I face? }\end{array}$ & $\begin{array}{l}\text { Online information and training/ } \\
\text { seminars } \\
\text { Active participation form lecturer } \\
\text { is important. } \\
\text { Tell students when you will be } \\
\text { available on the mobile learning } \\
\text { platform. }\end{array}$ \\
\hline $\begin{array}{l}\text { ICT } \\
\text { infrastructure }\end{array}$ & $\begin{array}{l}\text { Appropriate } \\
\text { infrastructure } \\
\text { to provide and } \\
\text { support mobile } \\
\text { learning. }\end{array}$ & $\begin{array}{l}\text { How will technical support } \\
\text { be made available? } \\
\text { What digital education measures } \\
\text { should be put in place? }\end{array}$ & $\begin{array}{l}\text { Produce online training and 'How } \\
\text { to' pages. Have regular seminars/ } \\
\text { training. }\end{array}$ \\
\hline Context & Of the activities & $\begin{array}{l}\text { Is the mobile learning activity } \\
\text { relevant? } \\
\text { Does it supplement or replace } \\
\text { any current activity? } \\
\text { How can I incorporate the activity } \\
\text { into the curriculum as part of my } \\
\text { regular teaching process? }\end{array}$ & $\begin{array}{l}\text { Ensure it is linked to real student } \\
\text { work. Learners are busy and may } \\
\text { find mobile learning less attractive } \\
\text { if it is not linked to their curriculum. }\end{array}$ \\
\hline
\end{tabular}

This aspect will help the practitioners set firm foundations for the mobile learning initiative, including the design and development requirements of a mobile application, if applicable. The guidelines related to the preliminary investigation include the following:

- Define firm foundations for the assessment feedback strategies.

Investigations should cover issues related to assessment and feedback culture, and policy and ICT infrastructure because these elements either support or affect the provision of assessment feedback.

- Pay attention to lecturers and students' issues, their devices and attitudes.

- Define foundations for ICT infrastructure that leverages the use of student-owned devices. 


\section{Pedagogical considerations and context guidelines}

Pedagogy is about the practices that influence the learning experience and, particularly, the assessment feedback experience. Context is about access to feedback anywhere, in authentic contexts, ensuring that the content is relevant, and thus, the need to embed mobile learning activities within the curriculum becomes crucial.

This section answers the part of the research question that asks: 'What pedagogical strategies can best be deployed to enhance student engagement with their assessment feedback and foster dialogic feedback communication channels between educators and students?'

In order to foster student engagement with feedback and enhance communication,

- Pay attention to the interaction and participation. As observed in this study, the interaction with the mobile web application results in a positive outcome when both lecturers and students participate.

- Enable choice and flexibility. Enable participants to make their own choices (anytime, anywhere and on any device).

- Provide personalised assessment feedback, which students prefer. Ensure the teaching and learning is tailored to individual needs. Provide the facilities that enable personalisation of student feedback.

- Provide pedagogical support and training so that educational technologies can be integrated into the lecturers' practices and embedded within the institution's learning management systems.

- Integrate the mobile learning assessment feedback practices into the curriculum and ensure the relevance of the mobile learning activities. An attempt to provide mobile learning activities that are not directly related to the curriculum will fail.

- Foster feedback culture changes by educating students on feedback prior to implementing the mobile learning strategy, which will help to enforce the idea behind the mobile learning strategy and the importance of students' participation in a feedback dialogue.

- Educators should reinforce the importance of feedback for student learning enhancement and subsequently to the institution as a whole.

- If you want to enable student engagement with their feedback, you are best advised to enable the assessment feedback in authentic contexts. These authentic contexts can be defined by the anywhere, anytime and using any device affordances that are brought by ownership. Feedback should be accessible in a formal and informal environment.

- The assessment feedback provided must be in context.

- Enable fostering of cultural changes by holding regular meeting sessions where staff and students can practice using the mobile learning platform. This will aid the teaching staff to overcome their fear of using the mobile learning platform or a new technology and encourage students to use their own devices.

- Measure the real, as opposed to the perceived, impacts of new technologies by considering digital footprinting, as seen in this study.

- Evaluate students' and educators' opinions of the feedback delivery method. This ensures that the relevancy of the learning activities has been established.

- Evaluate students: This will inform whether the educational goals are achieved. For example, engagement with feedback and communication. 
- Provide opportunities to share new practices with guidelines that provide direction and reassurance to staff about the assessment feedback practices. Promoting the benefits of using mobile learning for assessment feedback among the teaching staff is crucial for obtaining educators' acceptance and adoption of mobile learning.

- It is important to promote the benefits at the institution's conferences, as well as formal and informal meetings. In this study, the researcher attended several Teaching and Learning conferences organised by the university where the benefits of using MyFeedBack for assessment feedback were presented via posters. During the conference in June 2014, both the researcher and the main lecturer did a joint presentation entitled 'Using MyFeedBack mobile Web 2.0 system to understand the conundrum of unknown students' behaviour upon receipt of their assignment results'. The lecturer shared her experiences of reigniting assessment feedback engagement and dialogic feedback channels using MyFeedBack. This resulted in further one-to-one meetings with other lecturers interested in providing assessment feedback using an enabling mobile learning platform.

\section{Ownership}

Ownership is about students reclaiming control over the devices that suit their taste or convenience, along with the time they want to access their content, the place they want to access that content and the pace at which they interact with it. It is about student motivation and being in control of their choices in a student-centred environment. With regard to this aspect, the following should be taken into consideration:

- Enable student control of learning in a student-centred environment by creating device-agnostic activities.

\section{ICT infrastructure}

An appropriate ICT infrastructure is necessary as it will allow learners to be in control and have the choice and flexibility to access the learning content anywhere, anytime and using any device, which, subsequently, can increase communication and dialogue. This is also about the provision of digital education and technical support to lecturers and students. The design and implementation guidelines for the ICT infrastructure are as follows:

With regard to the design of the mobile web application for assessment feedback, the following should be taken into consideration:

- Ground the design of mobile learning platform for assessment feedback on insights gained from the results of the initial explorative studies.

With regard to the actual development of the mobile web application for assessment feedback, the following should be taken into consideration:

- If you want to design a mobile learning environment or appropriate the available ICT infrastructure for mobile learning assessment feedback, then you are best advised to design an enabling platform that will allow wide participation by letting students use any device of their choice, including their smartphones. 
- When introducing similar technology into educational settings, information about the technical requirements that would enhance its use must be explicitly provided to lecturers and students.

- Any changes in the functionality should be regularly reported, the usability of the application should be evaluated on several occasions in order to improve it and the use of a mobile web application to cater to the diversity in student device and their choice should be considered.

With regard to the implementation of the mobile web application for assessment feedback, the following should be taken into consideration:

- Maintain a constant interaction with the participants. This will increase the possibility of lecturers using the application and getting familiarised with its features.

- Educating the teaching staff on how to use the mobile learning platform for assessment feedback and communication will help to overcome confidence issues in the teaching staff about using a new form of technology-enhanced assessment feedback.

- Educate students on how to use their own mobile handheld device or any device of their choice for assessment feedback in order to overcome any resistance due to confidence and communication issues.

\section{Conclusions and future work}

This study contributes to the body of knowledge on assessment feedback in mobile learning through the development of a Mobile Learning Framework for Assessment Feedback (MLFAF). The framework highlights the importance of pedagogy and pedagogical practices as the core aspect of an environment that fosters the use of student-owned devices for assessment feedback. MLFAF is designed to provide educators, policy-makers and researchers with a representation of how student devices could be harnessed in the context of assessment feedback in order to increase their engagement and foster communication and feedback dialogue with their lecturers. It also provides a broader view that takes into account the key aspects to be considered, which are likely to succeed or may not succeed in any mobile learning implementation.

Practitioners are encouraged to consider using MLFAF to plan, develop and evaluate longitudinal mobile learning initiatives in different environments and in different disciplines. Further research might help to identify and explore the factors influencing engagement with the summative and formative assessment feedback, and how, or if, these affect the dynamics of the components of the framework.

Acknowledgements

The author very much appreciates the scholarly advice provided by Dr. Mark Stansfield from the University of the West of Scotland, UK.

Author's contributions

The author read and approved the manuscript. 


\section{Publisher's Note}

Springer Nature remains neutral with regard to jurisdictional claims in published maps and institutional affiliations.

\section{Received: 27 July 2017 Accepted: 12 April 2018}

Published online: 20 April 2018

\section{References}

Ahern, L, Feller, J, Nagle, T. (2016). Social media as a support for learning in universities: an empirical study of Facebook groups. Journal of Decision Systems, 25(sup1), 35-49 https://doi.org/10.1080/12460125.2016.1187421.

Alghamdi, AH, \& Li, L. (2013). Adapting design-based research as a research methodology in educational settings. International Journal of Education and Research, 1(10), 1-12 Retrieved from www.ijern.com/journal/October-2013/27.pdf.

Amiel, T, \& Reeves, TC. (2008). Design-based research and educational technology: rethinking technology and the research agenda. Educational Technology \& Society, 11(4), 29-40 Retrieved from https://www.researchgate.net/ publication/220374789_Design-Based_Research_and_Educational_Technology_Rethinking_Technology_and_the_ Research_Agenda.

Anderson, T, \& Shattuck, J. (2012). Design-based research: a decade of progress in education research? Educational Researcher, 41(1), 16-25 https://doi.org/10.3102/0013189X11428813.

Bailey, R, \& Garner, M. (2010). Is the feedback in higher education assessment worth the paper it is written on? Teachers' reflections on their practices. Teaching in Higher Education, 15(2), 187-198 Retrieved from https://www. tandfonline.com/doi/abs/10.1080/13562511003620019?journalCode=cthe20.

Barbara, HA. (2010). Student ownership: learning in a student-centered art room. Art Education, 63(4), 40-46. https://doi. org/10.1080/00043125.2010.11519078

Bell, AR, \& Brooks, C. (2017). What makes students satisfied? A discussion and analysis of the UK's national student survey. Journal of Further and Higher Education, 1-25. https://doi.org/10.1080/0309877X.2017.1349886.

Belshaw, D (2010). Mobile and wireless technologies review. Newcastle upon Tyne, UK: IISC infoNet.

Bikanga Ada, M. (2013a). MyFeedBack: an interactive mobile Web 2.0 system for formative assessment and feedback. Paper presented at the $2^{\text {nd }}$ International Conference on e-Learning and e-Technologies in Education, Lodz, Poland. Retrieved from http://ieeexplore.iee.org/document/6644355/

Bikanga Ada, M (2013b). Using student's own mobile handheld device for mobile learning: practical issues. In Proceedings of $6^{\text {th }}$ International Conference Of Education, Research and Innovation, Seville, Spain, 18-20 November 2013, (pp. 2487-2497) https://library.iated.org/view/BIKANGAADA2013USI.

Bikanga Ada, M. (2014a). Fostering students' 'use my own device' attitude. International Journal of Technology and Educational Marketing, 4(1), 15-33. https://doi.org/10.4018/ijtem.2014010102.

Bikanga Ada, M. (2014b). Using MyFeedBack application to statistically investigate students' feedback access. Proceedings of 56th International Symposium ELMAR (ELMAR 2014), Zadar, Croatia, 10-12 September 2014, 1-4, doi: https://doi.org/10.1109/ELMAR.2014.6923369

Bikanga Ada, M (2014c). Using MyFeedBack, a mobile web 2.0 system, to help students engage with their feedback - a case study at a Scottish university. In Proceedings of the 6th International Conference on Education and New Learning Technologies, Barcelona, Spain, 7-9 July 2014, (pp. 4910-4919) https://library.iated. org/publications/EDULEARN14.

Bikanga Ada, M (n.d.). Interrelationship between pedagogy, theories, objectives, and features: mobile learning design. In P Tripathi, S Mukerji (Eds.), Marketing initiatives for sustainable educational development. https://doi.org/10.4018/9781-5225-5673-2. IGl Global.

Bikanga Ada, M, \& Stansfield, M (2017). The potential of learning analytics in understanding students' engagement with their assessment feedback. Paper presented at the IEEE 17th International Conference on Advanced Learning Technologies (ICALT), Timisoara, Romania. Retrieved from http://ieeexplore.ieee.org/stamp/stamp.jsp?tp= \&arnumber=8001768\&isnumber=8001692. Accessed 19 Nov 2017.

Bikanga Ada, M, Stansfield, M, Baxter, G. (2017). Using mobile learning and social media to enhance learner feedback: some empirical evidence. Journal of Applied Research in Higher Education, 9(1), 70-90. https://doi.org/10.1108/ JARHE-07-2015-0060.

Black, P, \& Wiliam, D. (1998). Assessment and classroom learning. Assessment in Education: Principles, Policy \& Practice, 5(1), 7-74. https://doi.org/10.1080/0969595980050102.

Bloxham, S, \& Campbell, L. (2010). Generating dialogue in assessment feedback: exploring the use of interactive cover sheets. Assessment \& Evaluation in Higher Education, 35(3), 291-300. https://doi.org/10.1080/02602931003650045.

Boud, D, \& Molloy, E. (2013). Rethinking models of feedback for learning: the challenge of design. Assessment \& Evaluation in Higher Education, 38(6), 698-712. https://doi.org/10.1080/02602938.2012.691462.

Campbell, MLC, \& Morrison, AP. (2007). The subjective experience of paranoia: comparing the experiences of patients with psychosis and individuals with no psychiatric history. Clinical Psychology \& Psychotherapy, 14(1), 63-77. https:// doi.org/10.1002/cpp.510.

Charles, D, Charles, T, McNeill, M, Bustard, D, Black, M. (2011). Game-based feedback for educational multi-user virtual environments. British Journal of Educational Technology, 42(4), 638-654. https://doi.org/10.1111/j.1467-8535.2010.01068.x.

Cheon, J, Lee, S, Crooks, SM, Song, J. (2012). An investigation of mobile learning readiness in higher education based on the theory of planned behavior. Computers \& Education, 59(3), 1054-1064 doi:http://dx.doi.org/10.1016/j. compedu.2012.04.015

Corbeil, JR, \& Valdes-Corbeil, ME (2007). Are you ready for mobile learning? In Why it matters to higher education EDUCAUSE REVIEW Retrieved from https://er.educause.edu/articles/2007/4/are-you-ready-for-mobile-learning.

Crook, A, Mauchline, A, Maw, S, Lawson, C, Drinkwater, R, Lundqvist, K, Park, J. (2012). The use of video technology for providing feedback to students: can it enhance the feedback experience for staff and students? Computers \& Education, 58(1), 386-396 doi:http://dx.doi.org/10.1016/j.compedu.2011.08.025.

Dann, C, \& Allen, B (2013). Using mobile video technologies to enhance the assessment and learning of pre-service teachers in Work Integrated Learning (WIL). In Proceedings of Information Technology \& Teacher Education 
International Conference (SITE) 2013, Chesapeake, United States, 25-29 march 2013, (pp. 4231-4238) http://research. usc.edu.au/vital/access/manager/Repository/usc:10136.

Dearnley, C, Haigh, J, Fairhall, J. (2008). Using mobile technologies for assessment and learning in practice settings: a case study. Nurse Education in Practice, 8(3), 197-204 doi:http://dx.doi.org/10.1016/j.nepr.2007.07.003.

Deng, L, \& Tavares, NJ. (2013). From Moodle to Facebook: exploring students' motivation and experiences in online communities. Computers \& Education, 68, 167-176 doi:http://dx.doi.org/10.1016/j.compedu.2013.04.028.

Evans, C. (2013). Making sense of assessment feedback in higher education. Review of Educational Research, 83(1), 70120 https://doi.org/10.3102/0034654312474350.

Ferguson, P. (2011). Student perceptions of quality feedback in teacher education. Assessment \& Evaluation in Higher Education, 36(1), 51-62. https://doi.org/10.1080/02602930903197883.

Ferreira, JB, Klein, AZ, Freitas, A, Schlemmer, E (2013). Mobile learning: definition, uses and challenges. In LA Wankel, P Blessinger (Eds.), Increasing student engagement and retention using mobile applications: smartphones, Skype and texting technologies (cutting-edge technologies in higher education, volume 6 part D), (pp. 47-82). New York: Emerald Group Publishing Limited.

Ferrell, G. (2012). A view of the assessment and feedback landscape: baseline analysis of policy and practice from the JISC Assessment \& Feedback programme. Retrieved from http://www.jisc.ac.uk/media/documents/programmes/elearning/ Assessment/JISCAFBaselineReportMay2012.pdf. Accessed 20 May 2017.

Franklin, TJ. (2015). Embracing the future: empowering the 21st century educator. Procedia - Social and Behavioral Sciences, 176(0), 1089-1096 doi:http://dx.doi.org/10.1016/j.sbspro.2015.01.584.

Gan, CL, \& Balakrishnan, V. (2017). Enhancing classroom interaction via IMMAP_an interactive mobile messaging app. Telematics and Informatics, 34(1), 230-243 https://doi.org/10.1016/j.tele.2016.05.007.

Gaved, M., Kukulska-Hulme, A., Jones, A., Scanlon, E., Dunwell, I., Lameras, P., \& Akiki, O. (2013). Creating coherent incidental learning journeys on mobile devices through feedback and progress indicators. Paper presented at the 12th World Conference on Mobile and Contextual Learning (mLearn 2013), Doha, Qatar. Retrieved from http://www. qscience.com/doi/pdf/10.5339/qproc.2013.mlearn.13. Accessed 1 Dec 2016.

Gemmell, AMD, Finlayson, IG, Marston, PG. (2010). First steps towards an interactive real-time hazard management simulation. Journal of Geography in Higher Education, 34(1), 39-51 https://doi.org/10.1080/03098260902982419.

Harley, D, Winn, S, Pemberton, S, Wilcox, P. (2007). Using texting to support students' transition to university. Innovations in Education and Teaching International, 44(3), 229-241 https://doi.org/10.1080/14703290701486506.

Hepplestone, S, Glover, I, Irwin, B, Parkin, H. (2016). Setting out the role of feedback in the assessment process through both the student and tutor perspective. Practitioner Research in Higher Education, 10(1), 81-90 Retrieved from http://shura.shu.ac.uk/16585/.

Hsu, Y-C, \& Ching, Y-H. (2015). A review of models and frameworks for designing mobile learning experiences and environments. Canadian Journal of Learning and Technology, 41(3), 1-22 DOl: http://dx.doi.org/10.21432/T2V616.

Hsu, Y-C, Ching, Y-H, Snelson, C. (2014). Research priorities in mobile learning: an international Delphi study/Les priorités de recherche en matière d'apprentissage mobile: Une étude de Delphes internationale. Canadian Journal of Learning and Technology, 40(2), 1-22 DOl: http://dx.doi.org/10.21432/T2QP4X.

Imtinan, U, Chang, V, Issa, T (2013). Common mobile learning characteristics-an analysis of mobile learning models and frameworks. In Proceedings Of The International Conference Mobile Learning 2013, Lisbon, Portugal, 14 March 2013, (pp. 3-11) http://hdl.handle.net/20.500.11937/21348.

Jones, A, \& Issroff, K. (2007). Motivation and mobile devices: exploring the role of appropriation and coping strategies. ALT-J: Research in Learning Technology, 15(3), 247-258 Retrieved from http://repository.alt.ac.uk/728.

Jones, A., Issroff, K., Scanlon, E., Clough, G., McAndrew, P., \& Blake, C. (2006). Using mobile devices for learning in informal settings: is it motivating? Paper presented at the IADIS International Conference on Mobile Learning 2006, Dublin Ireland. Retrieved from http://oro.open.ac.uk/38919/. Accessed 18 May 201.

Kearney, M, Schuck, S, Burden, K, Aubusson, P. (2012). Viewing mobile learning from a pedagogical perspective. Research in Learning Technology, 20. https://doi.org/10.3402/rlt.v20i0.14406.

Khaddage, F, Christensen, R, Lai, W, Knezek, G, Norris, C, Soloway, E. (2015). A model driven framework to address challenges in a mobile learning environment. Education and Information Technologies, 20(4), 625-640. https://doi. org/10.1007/s10639-015-9400-X.

Khaddage, F, Müller, W, Flintoff, K. (2016). Advancing mobile learning in formal and informal settings via mobile app technology: where to from here, and how? Educational Technology \& Society, 19(3), 16-26 https://espace.curtin.edu. au/handle/20.500.11937/23273.

Kong, SC. (2015). An experience of a three-year study on the development of critical thinking skills in flipped secondary classrooms with pedagogical and technological support. Computers \& Education, 89(Supplement C), 16-31 https:// doi.org/10.1016/j.compedu.2015.08.017.

Koole, M, McQuilkin, JL, Ally, M. (2010). Mobile learning in distance education: utility or futility? Journal of Distance Education, 24(2), 59-82 http://files.eric.ed.gov/fulltext/EJ892387.pdf.

Koole, M. L. (2009). A model for framing mobile learning. In M. Ally (Ed.), Mobile learning: transforming the delivery of education and training (pp. 25-47). Retrieved from http://auspace.athabascau.ca/bitstream/2149/2016/1/02_ Mohamed_Ally_2009-Article2.pdf. Accessed 18 May 2017.

Kukulska-Hulme, A, Pettit, J, Bradley, L, Carvalho, AA, Herrington, A, Kennedy, DM, Walker, A. (2011). Mature students using mobile devices in life and learning. International Journal of Mobile and Blended Learning (IJMBL), 3(1), 18-52 http://oro.open.ac.uk/28367/1/kukulska_IJMBL.pdf.

Laurillard, D. (2007). Pedagogical forms for mobile learning: framing research questions. In N. Pachler (Ed.), Mobile learning: towards a research agenda (pp. 153-175). Retrieved from http://eprints.ioe.ac.uk/5402/1/mobilelearning pachler_2007.pdf. Accessed 29 Mar 2017.

Laurillard, D. (2009). The pedagogical challenges to collaborative technologies. International Journal of ComputerSupported Collaborative Learning, 4(1), 5-20. https://doi.org/10.1007/s11412-008-9056-2.

Lazar, J, Feng, JH, Hochheiser, H (2010). Research methods in human-computer interaction. United Kingdom: Wiley. 
Ledford, CJW, Saperstein, AK, Cafferty, LA, McClintick, SH, Bernstein, EM. (2015). Any questions? An application of Weick's model of organizing to increase student involvement in the large-lecture classroom. Communication Teacher, 29(2), 116-128 https://doi.org/10.1080/17404622.2014.1003309.

Li, J, \& De Luca, R. (2014). Review of assessment feedback. Studies in Higher Education, 39(2), 378-393. https://doi.org/10. 1080/03075079.2012.709494.

McKenney, SE, \& Reeves, TC (2012). Conducting educational design research. New York: Routledge.

Merchant, G. (2012). Mobile practices in everyday life: popular digital technologies and schooling revisited. British Journal of Educational Technology, 43(5), 770-782. https://doi.org/10.1111/j.1467-8535.2012.01352.x.

Mortimore, P. (1999). Understanding pedagogy: and its impact on learning. London: SAGE Publications.

Motiwalla, LF. (2007). Mobile learning: a framework and evaluation. Computers \& Education, 49(3), 581-596. https://doi. org/10.1016/j.compedu.2005.10.011.

Naismith, L. (2007). Using text messaging to support administrative communication in higher education. Active Learning in Higher Education, 8(2), 155-171 https://doi.org/10.1177/1469787407078000.

Nanney, B. (2004). Student-centered learning. Retrieved from http://ollyusofalhaj.ipgkti.edu.my/sumber/resosbestari/ PENDEKATAN/scl/7\%20SCL-Nanney.pdf. Accessed 17 May 2017.

Nicol, D, Thomson, A, Breslin, C. (2014). Rethinking feedback practices in higher education: a peer review perspective. Assessment \& Evaluation in Higher Education, 39(1), 102-122. https://doi.org/10.1080/02602938.2013.795518.

NSS. (2012). National Student Survey 2012. Retrieved from http://www.hefce.ac.uk/lt/nss/results/2012/. Accessed 8 May 2017.

Ozdamli, F. (2012). Pedagogical framework of m-learning. Procedia - Social and Behavioral Sciences, 31, 927-931 doi: http://dx.doi.org/10.1016/j.sbspro.2011.12.171.

Park, Y. (2011). A pedagogical framework for mobile learning: categorizing educational applications of mobile technologies into four types. International Review of Research in Open and Distance Learning, 12(2), 78 Retrieved from http://www.irrodl.org/index.php/irrodl/article/view/791/1699.

Parsons, D, Ryu, H, Cranshaw, M. (2007). A design requirements framework for mobile learning environments. Journal of Computers, 2(4), 1 Retrieved from http//citeseerx.ist.psu.edu/viewdoc/download?doi=10.1.1.131.6551\&rep=rep1\&type=pdf.

Parsons, D., Thomas, H., \& Wishart, J. (2016). Exploring mobile affordances in the digital classroom. Paper presented at the 12th International Conference on Mobile Learning (ML 2016), Almoura, Portugal. Retrieved from https://files.eric.ed. gov/fulltext/ED571455.pdf. Accessed 1 May 2017.

Pimmer, C, Mateescu, M, Gröhbiel, U. (2016). Mobile and ubiquitous learning in higher education settings. A systematic review of empirical studies. Computers in Human Behavior, 63, 490-501 https://doi.org/10.1016/j.chb.2016.05.057.

Price, M, Handley, K, Millar, J, O'Donovan, B. (2010). Feedback: all that effort, but what is the effect? Assessment \& Evaluation in Higher Education, 35(3), 277-289. https://doi.org/10.1080/02602930903541007.

Schuck, S, Kearney, M, Burden, K. (2017). Exploring mobile learning in the third space. Technology, Pedagogy and Education, 26(2), 121-137. https://doi.org/10.1080/1475939X.2016.1230555.

So, S. (2016). Mobile instant messaging support for teaching and learning in higher education. The Internet and Higher Education, 31, 32-42 https://doi.org/10.1016/j.iheduc.2016.06.001.

Soh, O-K, \& Ho, H-F. (2014). Students' perceptions towards the use of dialogic feedback in mobile applications for students' writing: a qualitative case study. Journal of e-Learning and Knowledge Society, 10(3), 37-49 https://www. learntechlib.org/d/150727/.

Sølvberg, AM, \& Rismark, M. (2012). Learning spaces in mobile learning environments. Active Learning in Higher Education, 13(1), 23-33. https://doi.org/10.1177/1469787411429189.

Sung, Y-T, Chang, K-E, Liu, T-C. (2016). The effects of integrating mobile devices with teaching and learning on students' learning performance: a meta-analysis and research synthesis. Computers \& Education, 94(Supplement C), 252-275 doi:https://doi.org/10.1016/..compedu.2015.11.008.

Taylor, C, \& Burke da Silva, K. (2014). An analysis of the effectiveness of feedback to students on assessed work. Higher Education Research \& Development, 33(4), 794-806. https://doi.org/10.1080/07294360.2013.863840.

Taylor, JD, Dearnley, CA, Laxton, JC, Coates, CA, Treasure-Jones, T, Campbell, R, Hall, I. (2010). Developing a mobile learning solution for health and social care practice. Distance Education, 31(2), 175-192. https://doi.org/10.1080/ 01587919.2010 .503343

Timmis, S. (2012). Constant companions: instant messaging conversations as sustainable supportive study structures amongst undergraduate peers. Computers \& Education, 59(1), 3-18 https://doi.org/10.1016/j.compedu.2011.09.026.

Traxler, J. (2010). The learner experience of mobiles, mobility and connectedness. Paper presented at the ELESIG Symposium: Digital Futures, University of Reading, UK. Retrieved from http://cloudworks.ac.uk/cloud/view/3472. Accessed 5 Nov 2016

Traxler, J (2011). Introduction. In J Traxler, J Wishart (Eds.), Making mobile learning work: case studies of practice, (pp. 412). Bristol: ESCalate The Higher Education Academy Subject Centre for Education University of Bristol Retrieved from http://escalate.ac.uk/8250.

Vavoula, G, \& Sharples, M. (2009). Meeting the challenges in evaluating mobile learning: a 3-level evaluation framework. International Journal of Mobile and Blended Learning (IJMBL), 1(2), 54-75. https://doi.org/10.4018/jmbl.2009040104.

Wang, F, \& Hannafin, MJ. (2005). Design-based research and technology-enhanced learning environments. Educational Technology Research and Development, 53(4), 5-23.

Wang, Y-S, Wu, M-C, Wang, H-Y. (2009). Investigating the determinants and age and gender differences in the acceptance of mobile learning. British Journal of Educational Technology, 40(1), 92-118. https://doi.org/10.1111/j. 1467-8535.2007.00809.x

Wishart, J., \& Green, D. (2010). Identifying emerging issues in mobile learning in higher and further education: a report to JISC. Retrieved from Bristol: http:/www.bristol.ac.uk/media-library/sites/education/migrated/documents/ emergereport.pdf. Accessed 5 Nov 2016. 